\title{
Dynamic Hedge Ratio Estimations in the European Union Emissions Offset Credit Market
}

\author{
John Hua Fan ${ }^{1}$ \\ Email: J.Fan@griffith.edu.au \\ Alexandr Akimov \\ Email: A.Akimov@griffith.edu.au \\ Eduardo Roca \\ Email: E.Roca@griffith.edu.au
}

Department of Accounting, Finance and Economics, Griffith Business School, Griffith University, Australia

\begin{abstract}
Following the introduction of the European Union Emissions Trading Scheme in 2005, the size of the carbon market has been growing at a tremendous rate. To meet the emissions reduction targets, the regulated parties can choose to participate in the allowance-based market by purchasing the spot allowances. Commencing in 2008, the regulated parties are also allowed to purchase the offset credits to meet their allowance limit. Given the risky nature of the offset credits, this paper evaluates the hedging performance of dynamic hedge ratios for the carbon offset credit (certified emissions reduction) market in the EU-ETS. To the best of our knowledge, this paper is the first attempt to evaluate the hedging performance of dynamic and constant hedge ratios in the carbon offset credit market. Based on the variance reduction and utility improvement measurements, the findings generally support the use of static hedge ratios over the more sophisticated, dynamic hedge ratios.
\end{abstract}

Key words: hedging, conditional hedge ratio; $\mathrm{CO} 2$; carbon emissions trading; risk management

\footnotetext{
${ }^{1}$ Corresponding author, Department of Accounting, Finance and Economics, Griffith University, Nathan, Queensland 4111, Australia. Tel. +61 (07) 37357671 Facsimile (07) 37353719

The authors thank anonymous referees, Nicholas Rohde, Ken Stewart and participants of $3^{\text {rd }}$ Asian Conference of International Association of Energy Economics in Kyoto University for their useful comments and suggestions.
} 


\section{Introduction}

The European Union Emissions Trading Scheme (EU-ETS) is the largest, most sophisticated greenhouse gas (GHG) emissions trading regime in the world today. The underlying GHG emission currently traded under the scheme is primarily carbon dioxide (CO2). The EU-ETS is a cap-and-trade system, involving multiple energy related sectors such as power stations, land based and offshore refineries, iron, steel, cement and lime production, paper, food and drink, glass, ceramics, engineering and manufacturing of vehicles (Directive 2003/87/EC, 2003). The scheme operates by placing a cap on the overall amount of $\mathrm{CO} 2$, companies are allowed to emit every year. In each compliance period, companies are allocated a certain amount of $\mathrm{CO} 2$ allowances based on their historical production outputs. To avoid a noncompliance penalty, companies that emit more than their awarded allowances will have to buy from companies that have a surplus of allowances. Therefore, as the overall cap continues to be tightened over time, the price of the allowances increases gradually due to the scarcity of supply. As the allowances become increasingly expensive, companies are forced to invest in alternative or cleaner technologies that mitigate their production of $\mathrm{CO} 2$ emissions. In return, companies receive offset credits which can also be used for compliance purposes. Thus, by design, the cap-and-trade system should cut $\mathrm{CO} 2$ emissions over the long run.

Unlike allowance-based trading ${ }^{2}$, the offset credits are generated by investing in GHG emissions reduction projects in either another Annex B party or a developing country which is a signatory to the Kyoto Protocol (United Nations, 1998, Article 6 and 12). Examples of such projects are renewable energy, clean technology and environmental sustainability projects, etc. These projects are referred to as Clean Development Mechanism (CDM) projects. The following Figure 1 shows the relationship between Clean Development Mechanism, Joint Implementation (JI) and offset credits.

\footnotetext{
${ }^{2}$ Represented by EUAs - units of emissions allowances issued by the European Union.
} 


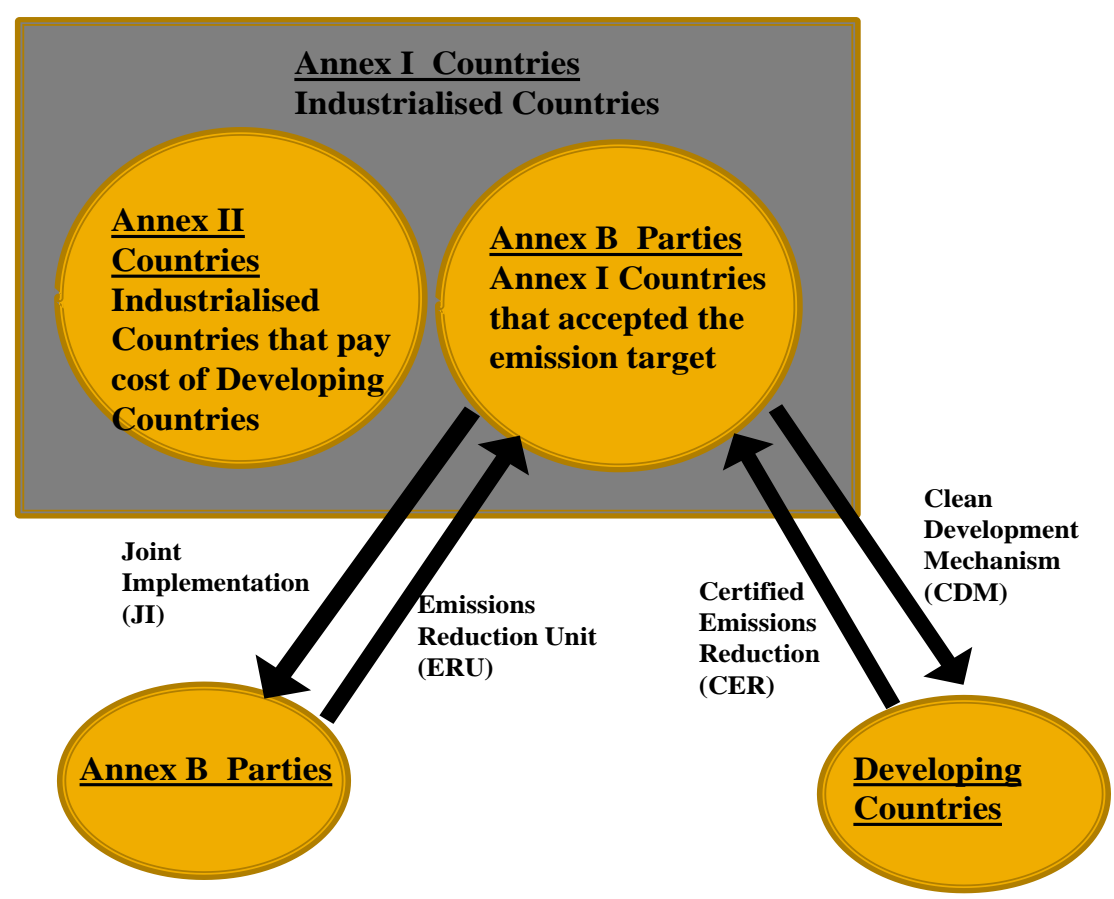

Figure 1 Relationship between CDM, JI and Offset Credits ${ }^{3}$

As shown in Figure 1, CDM is an investment made by an Annex B party to a developing country on a project that reduces carbon emissions or promotes other aspects of environmental sustainability. In return, the Annex B party receives project offset credit, referred to as Certified Emissions Reduction (CER). Applying similarly to JI, the Annex B party invests in another Annex B country which receives Emission Reduction Units (ERU). Both CER and ERU are equivalent to one tonne of $\mathrm{CO} 2$ and can be used towards meeting Kyoto Protocol targets. The primary CDM is the initial transaction between the project developer (seller of CERs) and the investor (buyer of CERs), which carries the CER from the project in the developing country to the industrialised countries. The secondary CDM market is any subsequent transaction after the initial transaction takes place, or the onward sale of the CER until eventually it reaches the final buyer, who will use it to meet its target.

Each CDM project can only go ahead when consent is reached between an industrialised country and a developing country that the project will indeed be contributing to sustainable development. Subsequently, the project applicant (i.e. the industrialised country) is required to demonstrate the additionality of the CDM project based on the methodologies of the CDM Executive Board. Additionality indicates that the project is able to carry out a reduction in carbon emission that would not otherwise have happened. A baseline level will be set in

\footnotetext{
${ }^{3}$ Annex II countries are a sub-group of Annex I countries including Australia, Austria, Belgium, Canada, Denmark, European Union, Finland, France, Germany, Greece, Iceland, Ireland, Italy, Japan, Luxembourg, Netherlands, New Zealand, Norway, Portugal, Spain, Sweden, Switzerland, Turkey, UK and USA.
} 
accordance with the estimate of future emissions in the absence of such projects. To ensure the authenticity and effectiveness of emission reductions in the long term, the case must be audited by Designated Operational Entity (DOE), an independent third party. The CDM Executive Board is in charge of the final approval of the project. If a project is given the green light, the board will then issue the primary CER credits to the applicant based on the difference between the actual emissions and the baseline level. Both government and private entities are eligible to hold CER credits. Once issued by the CDM Executive Board, CERs will be held on electronic accounts with the United Nations (UN).

CERs can be obtained from the primary market (i.e. purchased from the original CDM project applicant) or secondary market (resold from a market exchange). It is only when the CER is actually present in an operator's trading account that its monetary value can be realised via trades. Notably, the buyer of secondary CERs carries much less risk compared to the primary CER, as the secondary CER is already in existence, or its delivery has been guaranteed with a contractual replacement. As a result, secondary CERs are expected to be more expensive than primary CERs. The following Table shows the volume and value growth of the global CER market including both the primary and the secondary market from 2005 to 2010:

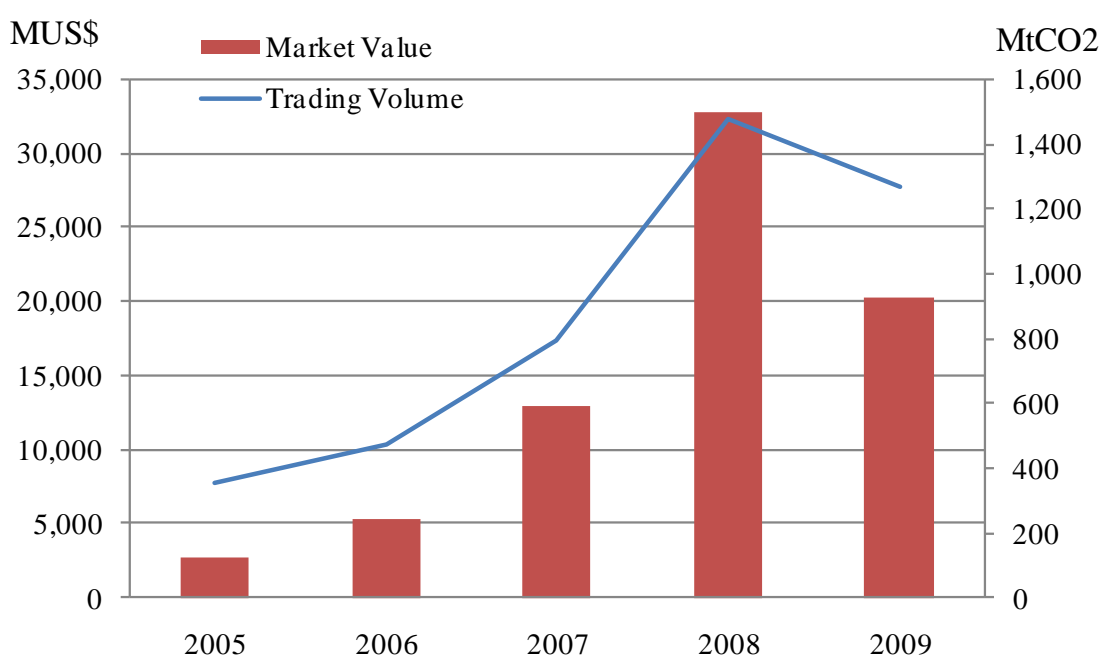

Figure 2 Trading Volume and Market Value of Global CER Market Data Source: World Bank (2005-2010)

As is evident from Figure 2, the global CER market demonstrated rapid growth. Despite a slight decrease of primary CDM in 2008 due to the global economic downturn, consistent increase in both trading volume and value of the CER market is recorded. The total market 
value of the CER market in 2009 increased by more than seven times since 2005 . The following Figure 3 indicates the primary CDM and JI buyers and sellers as shares of volume purchased in 2008.

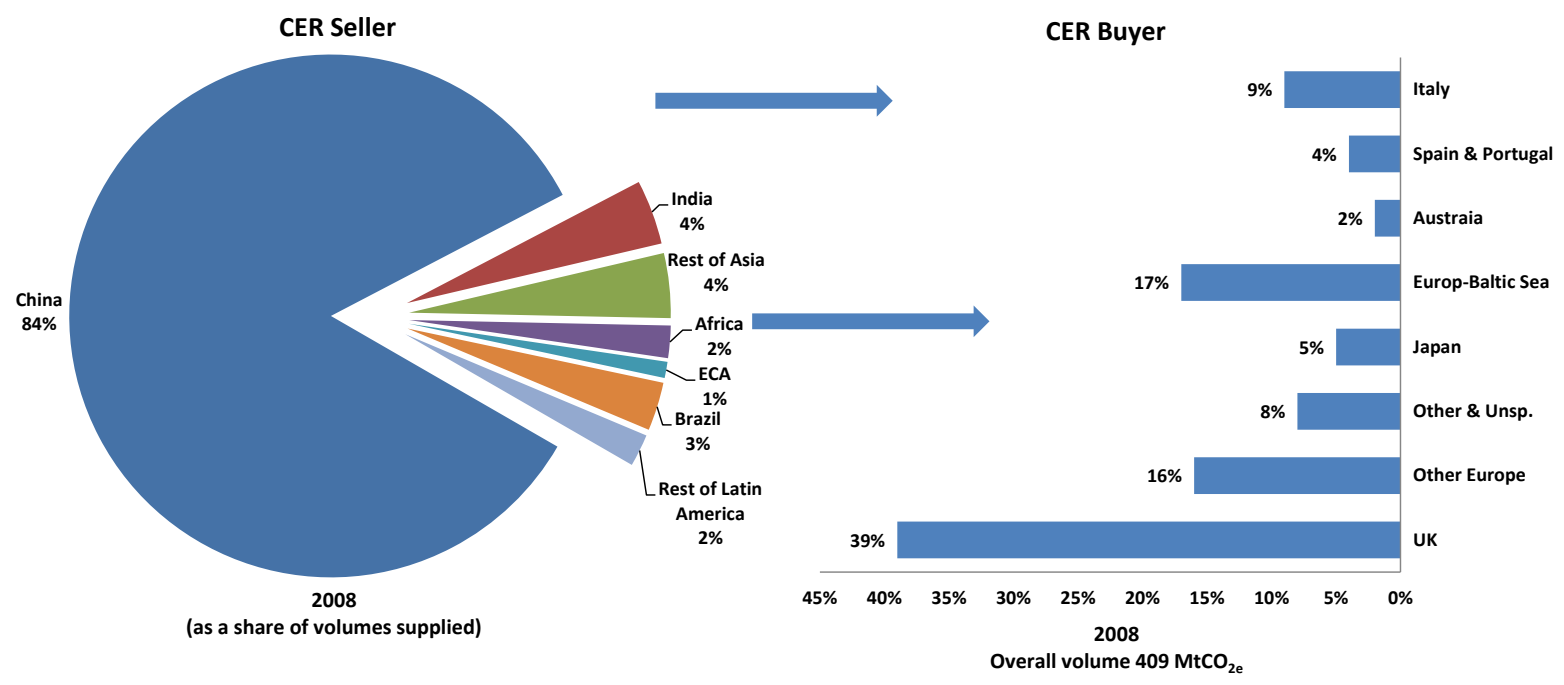

Figure 3. Distribution of Primary CDM \& JI Buyers and Sellers in 2008

Source: World Bank, 2009, p.33

Note: 'Unsp.' refers to purchases where the origin of the buyers could not be verified

Most notably, European countries accounted for over $80 \%$ of the market share, with the UK alone dominating the market at $39 \%$ of total purchase. On the supply side of primary CDM projects, China is the absolute dominator with a total number of 2,411 approved projects and a further 758 projects in the process of registration, as of 17th of March, 2010 (Clean Development Mechanism in China ${ }^{4}$, 2009). China began its domination of the project-based carbon market in 2005 and since then has consistently been the biggest seller of primary CDM. Moreover, Brazil and India are catching up quickly as they are the largest individual sellers after China, as of 2008.

The EU-ETS was introduced in January 2005. Currently three phases are set out in the scheme, Phase I (2005-2007), Phase II (2008-2012) and Phase III (2013-2020). The main instrument traded since inception is referred to as a European Union Allowance (EUA), where one unit of the EUA equals one tonne of CO2. In Phase II, in addition to EUAs, the Certified Emissions Reduction (CER) credits were introduced into the scheme (secondary $\mathrm{CDM}$ ) where one unit of CER is also one tonne of CO2. CER credits are the primary focus of this analysis.

\footnotetext{
${ }^{4}$ Clean Development Mechanism in China is sponsored by Department of Climate Change, National Development and Reform Commission (China's top economic planner).
} 
The EU-ETS was originally designed to cut greenhouse gas emissions and in the long run to mitigate the aggregate output of $\mathrm{CO} 2$ emissions by forcing the pollution-intensive industries to gradually transit to a cleaner and more sustainable state. Despite the apparent environmental motivation behind the EU-ETS, the cap-and-trade system is trapped by the inescapable nature of a market mechanism in which the risk and return relationship plays a central role. This is particularly the case for the regulated parties (i.e. energy companies, oil refineries, etc), which are forced to adopt suitable risk management practices. To meet the EU-ETS requirement, for each unit of $\mathrm{CO} 2$ that exceeds the allocation, polluters can either choose to purchase the spot EUA/secondary CER in the market or invest in a primary CDM project to receive a primary CER credit. Nevertheless, like any other market, the spot price of EUA and CER fluctuate on a daily basis, which makes EUA and CER fall into the category of risky assets.

To better manage the price risk, financial economists often engage in hedging using futures contracts. The hedge ratio computation is employed to determine the optimal amount of futures to be purchased in order to minimise the risk of unfavorable price fluctuations. The first rigorous study of hedging and hedge ratios can be found in Ederington (1979). Ederington (1979) employs the ordinary least squares (OLS) regression model to obtain a constant minimum variance (MV) optimal hedging ratio (OHR). Myers and Thompson (1989), Malliaris and Urrutia (1991) and Benet (1992) confirm Ederington's (1979) theory. However, the problem with OLS type hedge ratios is that it ignores the possible cointegration between spot and futures. Ghosh (1993), Chou, Fan and Lee (1996), Ghosh and Clayton (1996), Lien (1996) and Sim and Zurbruegg, (2001) among many others, adopted the Error Correction Model (ECM). As a result, not only statistically (based on likelihood ratio statistics) but also from the portfolio variance minimising aspect, the ECM-type hedge ratios outperform the OLS in Ederington's (1979) research.

The hedge ratio has been a fixed number throughout the entire hedging horizon until the introduction of time-varying heteroscedasticity (Engle, 1982). Baillie and Myers (1991) employed the BGARCH model for the hedging of six different commodities. Park and Switzer (1995) tested S\&P 500 and Toronto 35 index futures. Both studies found that the performance of a time-varying hedge ratio is far superior to a constant hedge ratio. Kroner and Sultan (1993) combined the bivariate ECM with the GARCH error structure and concluded that both within-sample and out-of-sample tests demonstrate that the proposed methodology is superior compared to the conventional method of currency hedging. 
In contrast, Bystrom (2003), Lien et al. (2002), Moosa (2003), Copeland and Zhu (2010) and a number of other critics have supported the validity of the OLS derived optimal hedge ratio with evidence showing that the OLS outperforms the more sophisticated methods. They also criticised, from a cost-and-benefit perspective, the complexity of the more sophisticated models, and questioned the practical application of such techniques due to the excessive transaction cost that arise from rebalancing the hedged portfolio. Thus, among all the hedge ratio estimation models discussed in this chapter, there is no universal agreement on which is the best one.

In the hedge ratio literature, there are virtually no known studies that examine the performance of dynamic hedge ratios in the carbon offset market. This may be explained by the fact that the market for CERs is new and relatively immature. This paper proceeds as follows: Section 2 discusses the data on certified emissions reduction followed by the methodology in Section 3. Empirical results are reported in Section 4 and the paper concludes with Section 5.

\section{Data}

To compute the optimal hedge ratio, we obtain both spot and futures data on CER traded under the EU-ETS. Spot CER price series are taken from BlueNext Exchange due to its popularity and reliability over the other sources. As trading of CER has only been introduced since Phase II of the EU-ETS, the time span for the CER's time series is from August 12, 2008 to December 20, 2010. Given the uniqueness of this market, Table 1 outlines the BlueNext spot contract specification in detail. 
Table 1 BlueNext Spot CER Contract Specification

\begin{tabular}{ll}
\hline Contracts & BlueNext Spot CER \\
\hline Mnemonic Code & BNS CER \\
Underlying & $\begin{array}{l}\text { CERs delivered by the Executive Committee of CDM's } \\
\text { Board, whose projects have been selected following the } \\
\text { advice of BlueNext's Expert Committee }\end{array}$ \\
& $0.01 € / \mathrm{t}$ \\
Price Tick & $0.01 € / \mathrm{t}$ \\
Minimum Price & 1,000 tonnes \\
Volume Tick & 1,000 tonnes \\
Minimum Volume & Continuous through Global Vision (Trayport) \\
Trading System & $8: 00$ am to 6:00 pm (UTC+1) Monday to Friday \\
Trading Hours & Registries interfacing with the delivery vs. payment \\
Delivery Place & scheme \\
& Delivery and Settlement operated by BlueNext in real \\
time. & Delivery consists of the transfer of the underlying from the \\
Settlement $\&$ & seller's account to the buyer's account via the Swiss \\
& registry for CER.
\end{tabular}

Futures contracts on CERs were originally introduced by the European Climate Exchange (ECX), one of the members of the Climate Exchange PLC (CLE). Prior to the acquisition by Intercontinental Exchange (ICE), ECX offered the most liquid contracts on both EU Allowances (EUAs) and CERs which account for over $85 \%$ of the exchange-traded volume in the European market. Officially speaking, futures contracts data used in this study are obtained from the ICE. The following Table 2 provides the futures contract specification.

Table 2 ICE ECX CER Futures Contract Specification

\begin{tabular}{|c|c|}
\hline Contracts & ICE ECX CER Futures Contract \\
\hline Unit of Trading & $\begin{array}{l}\text { One lot of 1,000 certified emission reduction units (i.e. 1,000 tonnes } \\
\text { of } \mathrm{CO} 2 \text { ) }\end{array}$ \\
\hline Quotation & Euro $(€)$ and Euro cent $(\mathrm{c})$ per metric tonne \\
\hline Min. Price Tick & 0.01 \\
\hline Contract months & $\begin{array}{l}\text { Contracts are listed on a quarterly expiry cycle such that March, June, } \\
\text { September and December contract months are listed up to December } \\
2012 \text { and March } 2013 \text {. }\end{array}$ \\
\hline Contract security & $\begin{array}{l}\text { ICE CLEAR EUROPE guarantees the financial performance of ICE } \\
\text { Futures Europe contracts registered in the name of its members. }\end{array}$ \\
\hline Trading system & $\begin{array}{l}\text { Trading will occur on the ICE Futures Europe platform accessible via } \\
\text { Web ICE, or through a conformed Independent Software Vendor }\end{array}$ \\
\hline Trading model & $\begin{array}{l}\text { Continuous trading between 07:00 hours to } 17: 00 \text { hours UK local } \\
\text { time. }\end{array}$ \\
\hline Settlement prices & $\begin{array}{l}\text { Trade weighted average during the daily closing period with Quoted } \\
\text { Settlement Prices if low liquidity. }\end{array}$ \\
\hline Delivery & $\begin{array}{l}\text { The contracts are physically deliverable by the transfer of emissions } \\
\text { allowances. } \\
\text { There is a delivery period of } 3 \text { days after the last trading day. }\end{array}$ \\
\hline
\end{tabular}

Technically, contracts are listed on a quarterly expiry cycle such that March, June, September and December contracts are available in a given year. However, March, June and September 
contracts suffer severe liquidity problems. Specifically, in the studied time period, there is either extremely small or no trading volumes at all on those contracts. In contrast, December contracts have much higher volumes traded, which should be sufficient to mitigate the liquidity concerns. Thus, for practical implications, we only use the December contracts (Dec-08, Dec-09 and Dec-10) for hedge ratio calculation and an effectiveness analysis. In terms of liquidity of the contracts, we have chosen Dec-09/10 to demonstrate the trading volume in the following Figure 4.
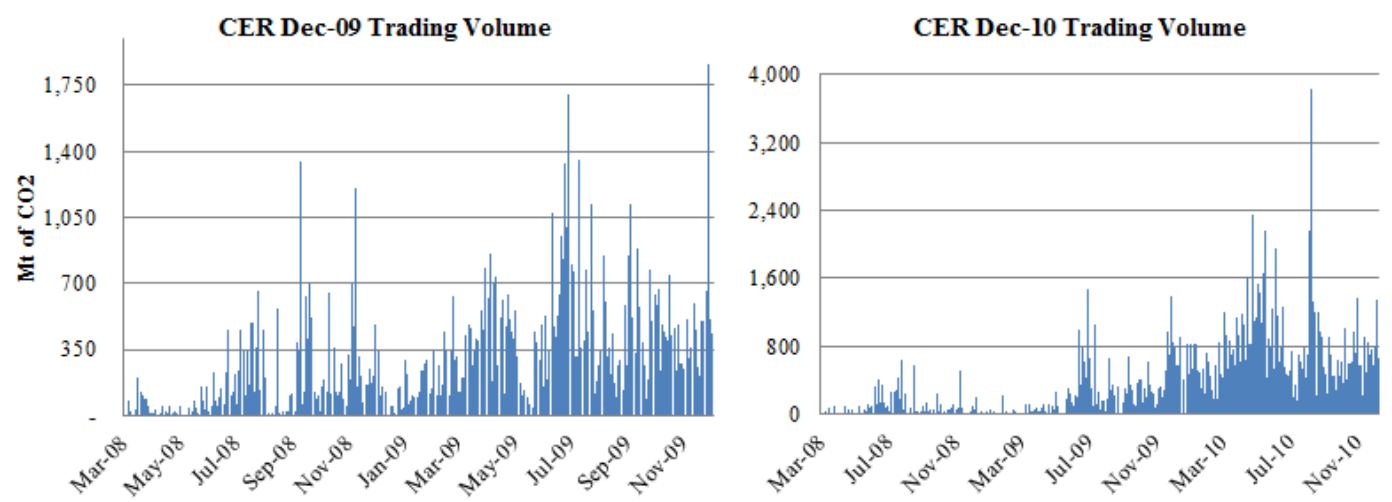

Figure 4 CER Futures Contract Trading Volume

It can be observed from Figure 4 that the trading volumes tend to be larger from around midyear. This is quite typical under the EU-ETS market environment, as the compliance requirements of $\mathrm{CO} 2$ have to be met on an annual basis. Therefore it is expected that the emitters will participate more actively in meeting their compliance needs when their production and emissions targets for the year can be accurately forecast. Given the uniqueness of the EU-ETS, we assume a maximum one-year hedging horizon for emitters in meeting their legally enforced compliance. This results in three hedge ratios, one for each year ending when the respective contract expires. As for the dynamic hedge ratios, the annual averages are reported.

Table 3 provides a descriptive statistics of CER spot and future prices in Panel A and continuously compounded return in Panel B. 
Table 3 Descriptive Statistics

\begin{tabular}{|c|c|c|c|c|c|c|c|c|c|c|c|}
\hline & & Obs. & Mean & Median & Max. & Min. & S.D. & Ske. & Kurt. & $\mathrm{J}-\mathrm{B}$ & Prob. \\
\hline \multicolumn{12}{|c|}{ Panel A: Price Level } \\
\hline \multirow{2}{*}{2008} & Spot & \multirow{2}{*}{89} & 17.493 & 18.800 & 20.900 & 13.180 & 2.550 & -0.322 & 1.506 & 9.815 & 0.007 \\
\hline & Futures & & 17.479 & 18.770 & 21.200 & 12.820 & 2.681 & -0.302 & 1.512 & 9.571 & 0.008 \\
\hline \multirow{2}{*}{2009} & Spot & \multirow{2}{*}{244} & 11.919 & 12.205 & 13.900 & 7.600 & 1.308 & -0.869 & 3.370 & 32.091 & 0.000 \\
\hline & Futures & & 11.815 & 12.120 & 13.820 & 7.390 & 1.371 & -0.974 & 3.515 & 41.268 & 0.000 \\
\hline \multirow{2}{*}{2010} & Spot & \multirow{2}{*}{251} & 12.534 & 12.340 & 14.590 & 10.970 & 0.823 & 0.356 & 1.996 & 15.842 & 0.000 \\
\hline & Futures & & 12.451 & 12.310 & 14.450 & 10.880 & 0.860 & 0.293 & 1.903 & 16.178 & 0.000 \\
\hline \multicolumn{12}{|c|}{ Panel B: First Difference } \\
\hline \multirow{2}{*}{2008} & Spot & \multirow{2}{*}{88} & -0.071 & -0.025 & 0.950 & -1.470 & 0.457 & -0.552 & 3.817 & 6.921 & 0.031 \\
\hline & Futures & & -0.073 & -0.055 & 0.880 & -1.460 & 0.452 & -0.658 & 3.662 & 7.950 & 0.019 \\
\hline \multirow{2}{*}{2009} & Spot & \multirow{2}{*}{243} & -0.001 & 0.000 & 0.820 & -0.910 & 0.299 & -0.214 & 3.514 & 4.531 & 0.104 \\
\hline & Futures & & -0.001 & 0.000 & 1.000 & -1.000 & 0.315 & -0.150 & 3.827 & 7.835 & 0.020 \\
\hline \multirow{2}{*}{2010} & Spot & \multirow{2}{*}{250} & 0.003 & 0.010 & 0.810 & -0.580 & 0.213 & 0.106 & 3.499 & 3.064 & 0.216 \\
\hline & Futures & & 0.002 & 0.000 & 0.840 & -0.560 & 0.211 & 0.114 & 3.785 & 6.964 & 0.031 \\
\hline
\end{tabular}

We have conducted various diagnostic tests (e.g. ADF and PP), which confirmed that all price level series are non-stationary. The co-integration between spot and futures appears to be strong, as suggested by the Engle-Granger test as well as Johansen's specification ${ }^{5}$.

\section{Methodology}

The lack of research on the hedge ratio estimation in the carbon market has forced us to turn back to the more "conventional" markets (i.e. stocks, bonds, currency and commodities) in terms of hedging ratio computation.

We assume the following setting for our hedging. The emitter who is concerned with breaching its limits for emissions and price risk of purchasing CER allowances at the end of a year at the spot market, purchases CERs at the futures market with the contract expiring at the end of the year. This is convenient from liquidity ${ }^{6}$ and reporting points of view as emissions are counted on the calendar year basis. Computation of hedge ratios is based on the following methods.

\subsection{Hedge Ratio Estimation}

\section{The Naïve Model}

The naïve approach to futures hedging is a one-to-one hedge ratio. In this approach for any

\footnotetext{
5 The results are not reported in the paper but are available upon request.

${ }^{6}$ December contracts are most liquid
} 
given spot position, an equal amount of futures positions are undertaken. Therefore, the hedge ratio will always be equal to one where each spot contract is offset by exactly one futures contract. The naïve hedge is heavily criticised for its inability to optimally hedge the spot position as it does not minimise the variance of the hedged portfolio.

\section{Ordinary Least Squares (OLS)}

Based on Ederington (1979), with a change in spot price being the dependent variable and the changes in futures price being the independent variable, the OLS model is given as:

$$
\Delta S_{t}=\alpha+\beta \Delta F_{t}+\varepsilon_{t}
$$

Where $\Delta S_{t}$ and $\Delta F_{t}$ is the continuous compounded return of spot and futures respectively, $\varepsilon_{t}$ is the error term and minimum variance hedge ratio is given as

$$
\beta=\frac{\operatorname{Cov}\left(\Delta S_{t}, \Delta F_{t}\right)}{\operatorname{Var}\left(\Delta F_{t}\right)}
$$

\section{Vector Error Correction Model (VECM)}

The OLS model hedge ratio is criticized for not taking into consideration the possibility that the spot and future price series could be non-stationary. If spot and futures are co-integrated, an error correction term should be added in the OLS model. Thus, we consider an error correction model. First, the long-run co-integrating equation is specified as:

$$
S_{t}=\beta_{0}+\beta_{1} F_{t}+\varepsilon_{t}
$$

where $\beta_{1}$ is the co-integration vector, $\beta_{0}$ is the constant term.

Second, insert the lagged regression residual from the co-integration equation into the VECM,

$$
\begin{aligned}
& \Delta S_{t}=\alpha_{10}+\alpha_{11} \widehat{\varepsilon}_{t-1}+\sum_{j=1}^{n} \varphi_{s 1 i} \Delta S_{t-j}+\sum_{i=1}^{m} \varphi_{s 2 i} \Delta F_{t-i}+v_{t}^{s} \\
& \Delta F_{t}=\alpha_{20}+\alpha_{21} \widehat{\varepsilon}_{t-1}+\sum_{j=1}^{n} \varphi_{f 1 i} \Delta S_{t-j}+\sum_{i=1}^{m} \varphi_{f 2 i} \Delta F_{t-i}+v_{t}^{f}
\end{aligned}
$$

Where: $\alpha_{10}$ and $\alpha_{20}$ are intercepts, $\varphi, \alpha_{11}$ and $\alpha_{21}$ are parameters, $v_{t}^{s}$ and $v_{t}^{f}$ are white-noise disturbance terms. $\hat{\varepsilon}_{t-1}=F_{t-1}-\beta_{0}-\beta_{1} S_{t-1}$, is the error correction term which measures how the dependent variable (in the vector) adjusts to previous long-term disequilibrium. The coefficients $\alpha_{11}$ and $\alpha_{21}$ is the speed of adjustment parameters. The more negative the $\alpha_{11}$ or $\alpha_{21}$, the greater the response of $\Delta S$ and $\Delta F$ to $\hat{\varepsilon}_{t-1}$, the previous periods disequilibrium. If 
we let, $\operatorname{Var}\left(v_{t}^{s}\right)=\sigma_{s s}, \operatorname{Var}\left(v_{t}^{f}\right)=\sigma_{f f}$ and $\operatorname{Cov}\left(v_{t}^{s}, v_{t}^{f}\right)=\sigma_{s f}$, the minimum variance hedge ratio is calculated as:

$$
h=\frac{\sigma_{s f}}{\sigma_{f f}}
$$

\section{VECM with GARCH-BEKK Error}

Standard OLS and VECM models assume the error term to have a mean of zero and a variance that is time-invariant. As spot and futures price time-series often display volatility that changes over time, we consider a model with a more relaxed assumption on the error term by allowing the second moment to be time-varying. To do this, a GARCH-BEKK error structure is inserted into equation 2 , the model specification becomes:

$$
\begin{aligned}
& \Delta S_{t}= \alpha_{10}+\alpha_{11} \widehat{\varepsilon}_{t-1}+\sum_{j=1}^{n} \varphi_{s 1 i} \Delta S_{t-j}+\sum_{i=1}^{m} \varphi_{s 2 i} \Delta F_{t-i}+\varepsilon_{t}^{s} \\
& \Delta F_{t}=\alpha_{20}+\alpha_{21} \widehat{\varepsilon}_{t-1}+\sum_{j=1}^{n} \varphi_{f 1 i} \Delta S_{t-j}+\sum_{i=1}^{m} \varphi_{f 2 i} \Delta F_{t-i}+\varepsilon_{t}^{f} \\
& \varepsilon_{t}=\left(\begin{array}{c}
\varepsilon_{t} \\
\varepsilon_{t}
\end{array}\right) \mid \Omega_{t-1} \sim D\left(0, H_{t}\right) \\
& H_{t}=C^{\prime} C+A^{\prime} \varepsilon_{t-1} \varepsilon_{t-1}^{\prime} A+B^{\prime} H_{t-1} B \\
& h_{s s, t}=c_{s s}+\alpha_{s s} \varepsilon_{s, t-1}^{2}+\beta_{s s} h_{s s, t-1} \\
& h_{s f, t}=c_{s f}+\alpha_{s f} \varepsilon_{s t-1} \varepsilon_{f t-1}+\beta_{s f} h_{s f, t-1} \\
& h_{f f, t}=c_{f f}+\alpha_{f f} \varepsilon_{f, t-1}^{2}+\beta_{f f} h_{f f, t-1}
\end{aligned}
$$

Where: $\hat{\varepsilon}_{t-1}$ is the error correction term, $\varepsilon_{t}$ is the error term of the VAR system, conditionally normally distributed with a mean of $(0,0)$, and a covariance matrix that is timevarying. Matrices $A, B$ and $C$ are parameter matrices and $C$ is a lower triangular. Matrices $A$ and $B$ are diagonal matrices. The $h^{*}$ optimal hedge ratio is computed as conditional covariance between spot return and futures divided by the conditional variance of futures return. Thus the minimum variance hedge ratio has now become time-varying; it varies with the changes in conditional covariance matrices:

$$
h^{*}=\frac{h_{s f}}{h_{f f}}
$$

Tailing the hedge 
The potential problem arises with hedging using futures contracts. Since they are subject to daily marking-to-market cash requirements, adjustment should be made to reflect these daily cash flows known as 'tailing' the hedge concept (Kawaller and Koch, 1988). These cash flows are funds borrowed to cover losses and funds invested when gains are accumulated. The tailing adjustments reduce the size of hedge ratios by the factor $1 /(1+i)^{\mathrm{T}}$ and can be significant for longer hedges (Hilliard and Huang, 2005; Lien, 2003) .

For our empirical testing we assume no daily marking-to-market, so hedge ratios are not tailed. In principle, simple adjustment for hedge ratios estimated by a regression is not possible since those hedge ratios are partially, but not completely tailed (Figlewski, Landskroner and Silber 1991).

\subsection{Hedging Effectiveness Measure}

\section{Variance Reduction}

To calculate the percentage variance reduction, the difference in variance of an unhedged portfolio and each hedged portfolio (constructed using different hedge ratios resulting from diverse models) is divided by the variance of the unhedged portfolio, as follows:

$$
V R=\frac{\operatorname{VAR}\left(\Delta S_{t}\right)-\operatorname{VAR}\left(\Delta S_{t}-h^{*} \Delta F_{t}\right)}{\operatorname{VAR}\left(\Delta S_{t}\right)}=1-\frac{\operatorname{VAR}\left(\Delta S_{t}-h^{*} \Delta F_{t}\right)}{\operatorname{VAR}\left(\Delta S_{t}\right)} \quad(\mathrm{Eq} 4)
$$

Where: $h^{*}$ is the computed hedge ratios derived from different hedge ratio estimation models, $\Delta S_{t}=S_{t}-S_{t-1}$ are the changes of spot price, which is also the return of the unhedged portfolio, $\Delta F_{t}=F_{t}-F_{t-1}$ are the changes of futures price, $\operatorname{VAR}\left(\Delta S_{t}-h^{*} \Delta F_{t}\right)$ is the variance of the hedged portfolio, and $\operatorname{VAR}\left(\Delta S_{t}\right)$ is the variance of the unhedged portfolio.

In line with Lien's (2005a, 2005b, 2009) theoretical contributions, we expect OLS measures to outperform more sophisticated hedge ratios unless there is a structural break in the data. Since hedge ratios are calculated within a single phase (Phase II), no structural break problems are expected.

\section{Utility Improvement}

The variance reduction motivated measurement for hedge ratio effectiveness is often criticised for not taking into account the utility of the hedger. To address this concern, we 
implement a second measurement for hedging effectiveness. In addition to the consideration of variance, the utility maximization method incorporates the risk aversion of investors. Using this method, the level of investors' utility that computed differently from the hedged portfolio is compared and ranked by the degree of utility improvement from the unhedged portfolio. The objective function that maximises the utility is given as:

$$
\operatorname{MAX}\left[E\left(R_{h} \mid \Omega_{t-1}\right)-\frac{1}{2} \phi \operatorname{Var}\left(R_{h} \mid \Omega_{t-1}\right)\right]
$$

Where: $R_{h}$ is the hedged portfolio $\left(\Delta S_{t}-h^{*} \Delta F\right), E\left(R_{h}\right)$ is the return of the hedged portfolio, $\operatorname{Var}\left(R_{h}\right)$, is the variance of the hedged portfolio, $\phi$ is the investors' level of risk aversion, $\Omega_{t-1}$ is the information set at time $\mathrm{t}-1$. We assume three levels of risk aversion which ranges from 1 to 3, where 1 reflects an investor with a low level, 2-a moderate and 3 - an investor with a high level of risk aversion. The utility level for the hedged and unhedged portfolios is computed from the portfolio's mean and variance of return.

\section{Empirical Results}

We introduce this section by presenting calculated hedge ratios in Table 4. Hedge ratios computed using naïve, OLS and VECM are constant and time-invariant, and these ratios remain entirely unchanged throughout each hedging horizon. By contrast, since VECMGARCH-BEKK assume a conditional variance and covariance matrix, the calculated hedge ratios are dynamic and time-varying. These ratios are not fixed, but are adjusted constantly on a daily basis throughout each hedging horizon. Therefore, for comparative reasons, we present the average result. 
Table 4 Calculated Hedge Ratios

\begin{tabular}{cccccc} 
Hedging & Futures & Naïve & Simple & Vector & VECM \\
Horizon & Contract & Appoach & OLS & ECM & GARCH* \\
\hline 2008 & Dec-08 & 1.0000 & 0.9431 & 0.8929 & 0.7949 \\
2009 & Dec-09 & 1.0000 & 0.8951 & 0.8839 & 0.9099 \\
2010 & Dec-10 & 1.0000 & 0.9419 & 0.9499 & 0.9779 \\
\hline
\end{tabular}

The calculated hedge ratios in Table 4 vary from model to model and from year to year. Despite the differences in model specification, ratios within a hedging horizon appear to be quite close. Since the optimal hedge ratio is calculated by dividing the covariance between spot and futures continuous compounded return by the variance of the futures return, any influences on the covariance and variance would ultimately affect the value of the ratios. Naturally, the price behavior of CER spot and futures has become the focus of discussion. To gain a deeper understanding of the OLS and VECM derived time-invariant hedge ratios, we plot the CER price series and the respective futures contracts series in Figure 5.

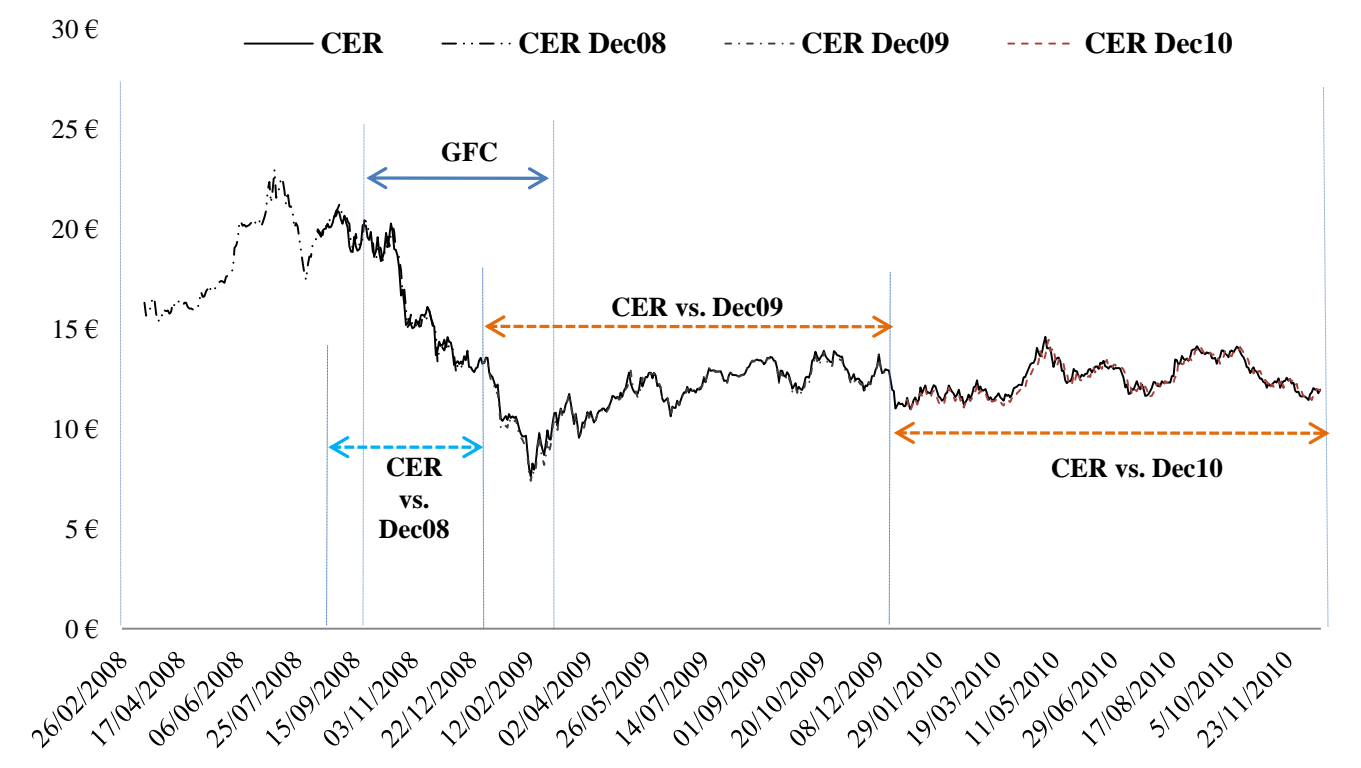

Figure 5 CER Spot and Futures by Hedging Horizon

The three hedging horizons are indicated separately. The heavier plotted broken line represents the spot CER price and the lighter dotted lines represent futures contracts. Noticeably, there is a clear decreasing trend from the second half of 2008 to the beginning of 2009, which coincides with the worst period in the global financial crisis. Hedging horizon 2008 suffers substantially from the GFC as spot and futures exhibit excessive volatility (measured by standard deviation in Table 3). With the global economy starting to recover in early 2009, CER and futures gain slightly. The volatility of spot and futures in hedging 
horizon 2009 decreases, yet is still above hedging horizon 2010 where the standard deviation is the lowest.

Figure 6 plots changes in spot and futures prices over the three annual periods. We can clearly see high volatility in 2008 and the beginning of 2009 prices - the peak period of the Global Financial Crisis. Price changes exhibit much lower volatility after that.

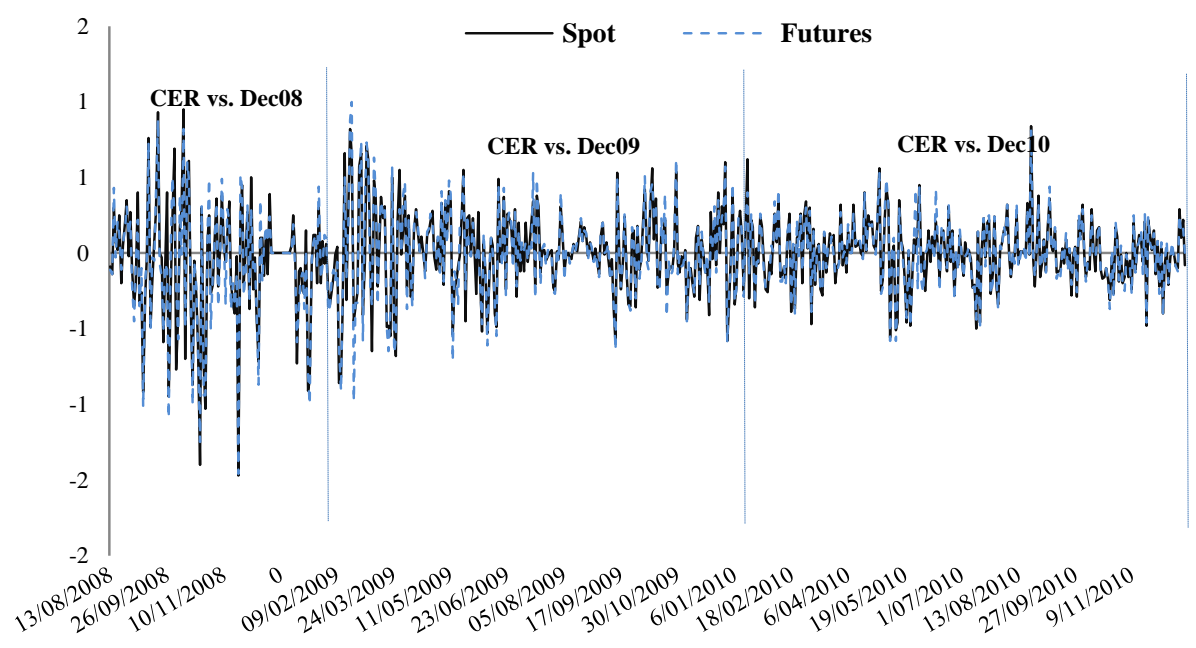

Figure 6 CER Spot and Futures Price Changes

A critical point to note here is that the covariance and variance are assumed to be constant, time-invariant. In other words, the constant optimal hedge ratios derived using OLS and VECM are designed to minimise the unconditional variance in a particular time horizon. Unlike OLS and VECM, the VECM with GARCH error structure produces a conditional, time-varying covariance matrix. Figures 7-9 demonstrate the dynamic hedge ratios for each hedging horizon. Every figure consists of two subsections. The first subsection shows the conditional covariance between spot and futures returns as well as the conditional variance of futures return. The second subsection is the time-varying hedge ratio. Plotting the covariance, variance and returns series allows us to clearly see the interactions between variations in time-varying hedge ratios and their determinants. 
Dynamic Covariance and Variance

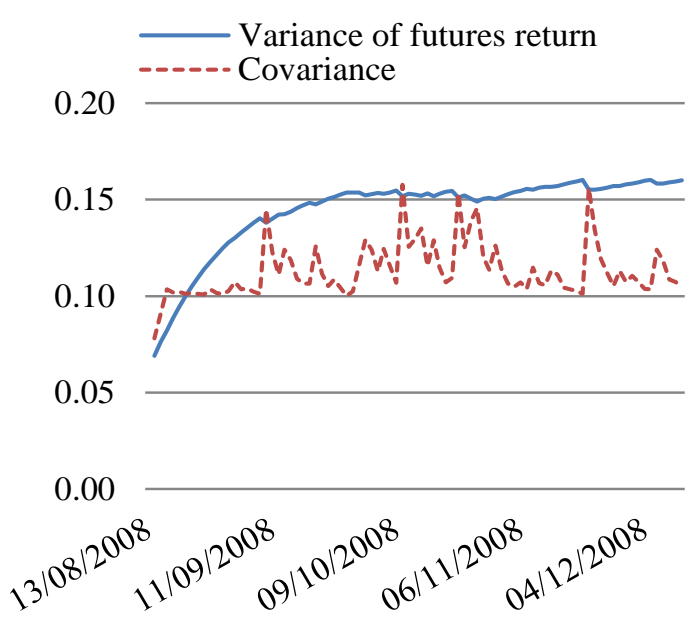

Dynamic Hedge Ratio-2008

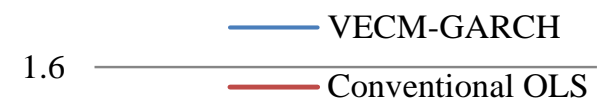

1.2

0.8

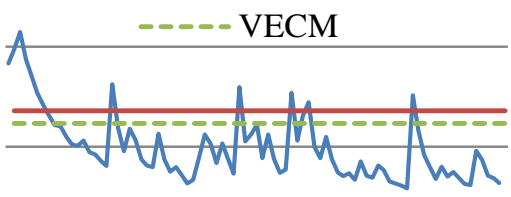

0.4

0.0

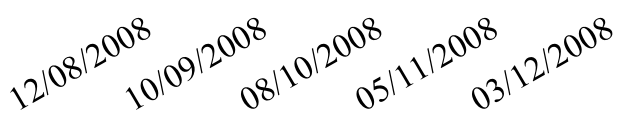

Figure 7. Time-varying Hedge Ratio and Determinants in 2008

In Figure 7, both variance of futures return appear to be flat after a slight increase at the beginning of the hedging horizon, whereas the conditional covariance between spot and futures return is mostly below conditional variance and varies at the order of 0.10 and 0.15 units. This in turn has led to a dynamic hedge ratio of less than one most of the time. In Figure 8, the dynamic covariance and variance has become much more volatile. This is likely to be caused by uncertainty in the market as a result of GFC. The dynamic hedge ratio, in contrast, does not vary so much since variation in dynamic covariance and dynamic variance of futures returns is similar.

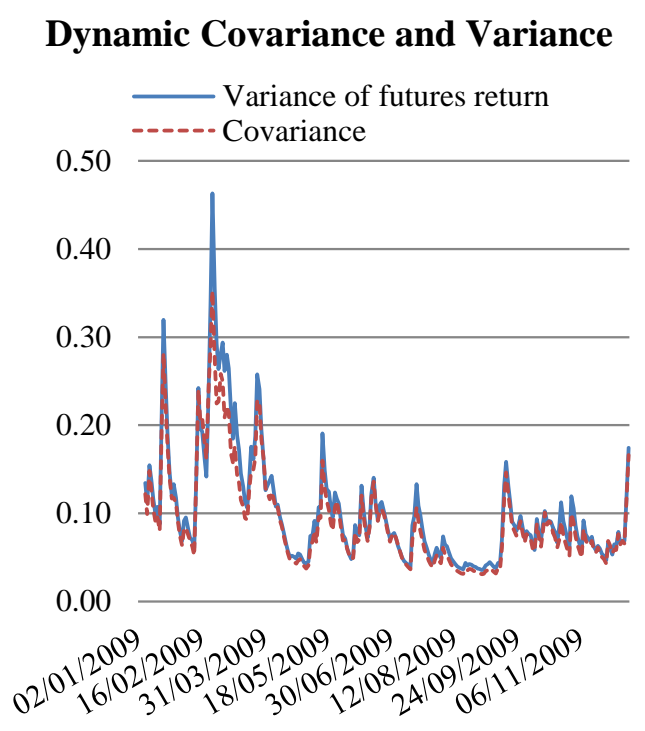

\section{Dynamic Hedge Ratio-2009}

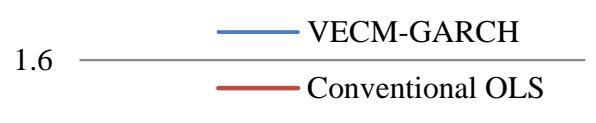

1.2

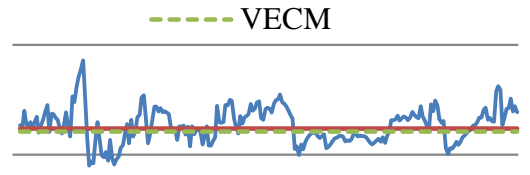

0.4

0

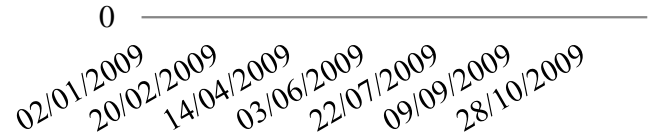

Figure 8. Time-varying Hedge Ratio and Determinants in 2009 
Compared to the 2008 and 2009 hedging horizons, the time-varying hedge ratio in Figure 9 appears to be "calmer". This can be explained by the small disparity in variation of dynamic covariance and dynamic variance of the futures returns.

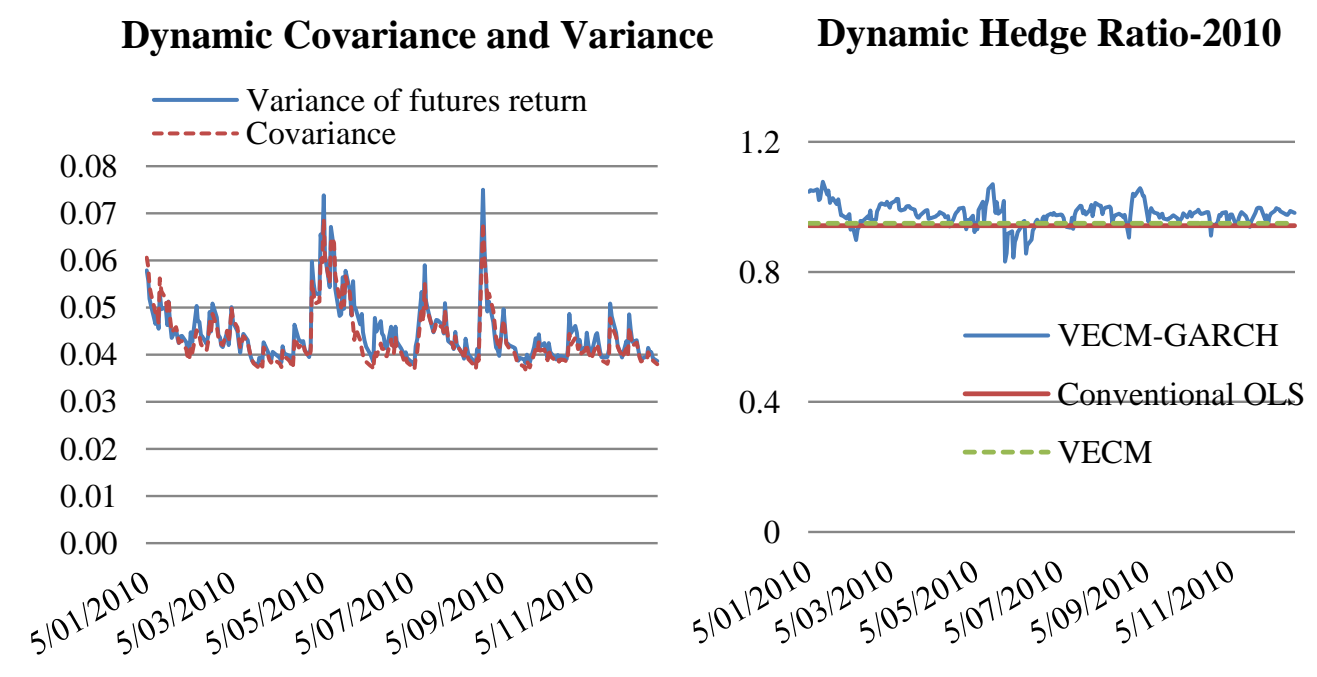

Figure 9. Time-varying Hedge Ratio and Determinants in 2010

\section{Hedging Effectiveness Measurement}

\section{Variance Reduction}

Table 5 reports how effective every model has been in terms of variance reduction for each hedging horizon. In terms of variance reduction, all four models have achieved the objective of variance reduction, whereas the OLS outperforms the other models overall. It comes best in 2008, whereas in 2009 and 2010 it is second best only to VECM GARCH. The smallest reduction is greater than 82 percent of the unhedged position while the largest reduction is just over 90 percent. The VECM-GARCH performs the worst in 2008 hedging horizon, but the best in 2009 and 2010. Not surprisingly the naïve model performs the worst overall. Although the naïve model provides the worst results, the variance reduction is not too far away from OLS and VECM. For unsophisticated hedgers, this can be used as an argument to justify a full hedge due to its simplicity. 
Table 5 Variance Reductions by Model

\begin{tabular}{|c|c|c|c|c|c|c|}
\hline \multirow[b]{2}{*}{$\begin{array}{l}\text { Hedging } \\
\text { Horizon }\end{array}$} & \multirow[b]{2}{*}{$\begin{array}{l}\text { Futures } \\
\text { Contracts }\end{array}$} & \multirow[b]{2}{*}{$\begin{array}{l}\text { Variance } \\
\text { Unhedged }\end{array}$} & \multicolumn{4}{|c|}{ Hedged Portfolio Variance Based On } \\
\hline & & & Naïve & OLS & VECM & $\begin{array}{c}\text { VECM } \\
\text { GARCH }\end{array}$ \\
\hline \multirow[t]{3}{*}{2008} & Dec-08 & 0.2085 & 0.02713 & 0.02647 & 0.02698 & 0.03682 \\
\hline & \multirow{2}{*}{ Variance } & \multirow{2}{*}{ e Reduced } & $\underline{0.18139}$ & $\underline{0.18206}$ & $\underline{0.18154}$ & $\underline{0.17171}$ \\
\hline & & & $86.99 \%$ & $\underline{\underline{87.31 \%}}$ & $\underline{\underline{87.06 \%}}$ & $\underline{\underline{82.34 \%}}$ \\
\hline \multirow[t]{3}{*}{2009} & Dec-09 & 0.0894 & 0.01088 & 0.00977 & 0.00978 & 0.00825 \\
\hline & \multirow{2}{*}{ Variance } & & $\underline{0.07855}$ & $\underline{0.07966}$ & $\underline{0.07965}$ & $\underline{0.08118}$ \\
\hline & & & $87.83 \%$ & $\overline{89.07 \%}$ & $89.06 \%$ & $\overline{90.77 \%}$ \\
\hline \multirow[t]{3}{*}{2010} & Dec-10 & 0.04493 & 0.00470 & $\overline{0.00455}$ & $\overline{0.00456}$ & $\overline{0.00452}$ \\
\hline & \multirow{2}{*}{ Variance } & & $\underline{0.04023}$ & $\underline{0.04037}$ & $\underline{0.04037}$ & $\underline{0.04040}$ \\
\hline & & Red & $89.54 \%$ & $89.86 \%$ & $\underline{89.86 \%}$ & $89.94 \%$ \\
\hline
\end{tabular}

These findings are in line with findings of other authors such as Bystrom (2003), Copeland and Zhu (2010), Lien et al. (2002) and Moosa (2003), which found that more sophisticated GARCH models show little or no improvement over simple OLS. As Lien (2009) points out, the hedge effectiveness measurement is based upon the unconditional (time-invariant) variance. While the VECM-GARCH derived conditional hedge ratio attempts to minimize the conditional (time-varying) variance, the conventional OLS derived hedge ratio aims to minimize the unconditional (time-invariant) variance. Thus OLS shall perform the best in most estimations with the exception of the smaller samples where a sufficient large variation of a conditional variance of the futures return is observed. This is the case for 2009 (see Figure 8) and at the lesser degree in 2010 (See Figure 9) hedging horizons. In 2008, as evident from Figure 7, the dynamic variance of futures return experiences only minor fluctuations. Therefore, the results in this study are generally in line with the existing literature. Since the pure variance reduction approach of performance evaluation is criticized for not taking utility into account, we also incorporate the utility factor into the evaluation process.

\section{Maximum Utility}

Table 6 shows the utility improvements achieved by different models with investors' risk aversion levels ranging from 1 to 3. A higher risk aversion level indicates investors are more risk-averse i.e. prefers lower risk given the level of expected return. After taking into account the return of the hedged portfolio, a clear pattern emerged. Within a given hedging horizon, the performance of each model in terms of utility improvement is independent of the investor's risk aversion level. Moreover, the results are very similar to the results obtained from variance reduction analysis. VECM-GARCH is the worst performer in 2008 on utility 
improvement while it is the best performer in the 2009 hedging horizon. Notably, this result confirms findings based on variance reduction capabilities that the OLS outperforms the other models (as it most frequently produces the highest utility improvement), in turn suggesting robustness of the findings. Yang and Allen (2004) report a similar finding in their in-sample results; that as the risk aversion level increases from 1 to 3 , utility improvement based on OLS tends to decrease. Overall, all hedging strategies (with the exception of VECM GARCH in 2008) provide strong utility improvements in order of $85-90 \%$ with only minor differences between them.

Table 6 Utility Improvements by Model

\begin{tabular}{|c|c|c|c|c|c|c|}
\hline \multirow[b]{2}{*}{$\begin{array}{l}\text { Hedging } \\
\text { Horzion }\end{array}$} & \multirow[b]{2}{*}{$\begin{array}{l}\text { Futures } \\
\text { Contracts }\end{array}$} & \multirow[b]{2}{*}{$\begin{array}{c}\text { Utility } \\
\text { Unhedged }\end{array}$} & \multicolumn{4}{|c|}{ Utility Improvement Based On } \\
\hline & & & Naïve & OLS & \multirow[t]{2}{*}{ VECM } & $\begin{array}{c}\text { VECM } \\
\text { GARCH }\end{array}$ \\
\hline \multicolumn{6}{|c|}{ Risk Aversion $=1$} & \\
\hline \multirow[t]{3}{*}{2008} & \multirow[t]{3}{*}{ Dec-08 } & -0.1749 & -0.0111 & -0.0149 & -0.0188 & -0.0416 \\
\hline & & & $\underline{0.1639}$ & $\underline{0.1600}$ & $\underline{0.1561}$ & $\underline{0.1333}$ \\
\hline & & uninty improved & $\underline{\underline{93.67 \%}}$ & $\underline{\underline{91.48 \%}}$ & $\underline{\underline{89.24 \%}}$ & $\underline{76.19 \%}$ \\
\hline \multirow[t]{3}{*}{2009} & \multirow[t]{3}{*}{ Dec-09 } & -0.0472 & -0.0049 & -0.0047 & -0.0047 & -0.0039 \\
\hline & & mproved & $\underline{0.0423}$ & $\underline{0.0425}$ & $\underline{0.0425}$ & $\underline{0.0433}$ \\
\hline & & & $\underline{89.56 \%}$ & $\underline{\underline{90.11 \%}}$ & $\underline{\underline{90.03 \%}}$ & $\underline{91.67 \%}$ \\
\hline \multirow[t]{3}{*}{2010} & \multirow[t]{3}{*}{ Dec-10 } & -0.0191 & -0.0028 & -0.0026 & -0.0026 & -0.0027 \\
\hline & & $\mathrm{I}$ & $\underline{0.0163}$ & $\underline{0.0165}$ & $\underline{0.0165}$ & $\underline{0.0164}$ \\
\hline & & $\mathrm{U}$ & $85.37 \%$ & $\underline{86.44 \%}$ & $\underline{86.35 \%}$ & $\underline{85.71 \%}$ \\
\hline \multicolumn{7}{|c|}{ Risk Aversion $=2$} \\
\hline \multirow[t]{3}{*}{2008} & \multirow[t]{3}{*}{ Dec-08 } & -0.2792 & -0.0246 & -0.0281 & -0.0323 & -0.0601 \\
\hline & & & $\underline{0.2546}$ & $\underline{0.2511}$ & $\underline{0.2469}$ & $\underline{0.2192}$ \\
\hline & & & $\underline{\underline{91.18 \%}}$ & $\underline{\underline{89.92 \%}}$ & $\underline{\underline{88.42 \%}}$ & $\underline{\underline{78.49 \%}}$ \\
\hline \multirow[t]{3}{*}{2009} & \multirow[t]{3}{*}{ Dec-09 } & -0.0921 & -0.0104 & -0.0096 & -0.0096 & -0.0081 \\
\hline & & $\mathrm{U}$ & $\underline{0.0817}$ & $\underline{0.0825}$ & $\underline{0.0825}$ & $\underline{0.0840}$ \\
\hline & & $\mathrm{d}$ & $\underline{\underline{88.72 \%}}$ & $\underline{\underline{89.61 \%}}$ & $\underline{\underline{89.56 \%}}$ & $\underline{91.25 \%}$ \\
\hline \multirow[t]{3}{*}{2010} & \multirow[t]{3}{*}{ Dec-10 } & -0.0415 & -0.0051 & -0.0049 & -0.0049 & -0.0050 \\
\hline & & Utility & $\underline{0.0363}$ & $\underline{0.0366}$ & $\underline{0.0366}$ & $\underline{0.0365}$ \\
\hline & & 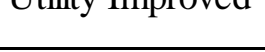 & $\underline{87.60 \%}$ & $\underline{\underline{88.29 \%}}$ & $\underline{\underline{88.24 \%}}$ & $\underline{87.99 \%}$ \\
\hline \multicolumn{7}{|c|}{ Risk Aversion $=3$} \\
\hline \multirow[t]{3}{*}{2008} & \multirow[t]{3}{*}{ Dec-08 } & -0.3835 & -0.0382 & -0.0414 & -0.0458 & -0.0785 \\
\hline & & Utility I & $\underline{0.3453}$ & $\underline{0.3421}$ & $\underline{0.3377}$ & $\underline{0.3050}$ \\
\hline & & 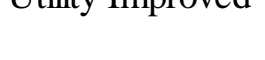 & $\underline{\underline{90.04 \%}}$ & $\underline{\underline{89.21 \%}}$ & $\underline{\underline{88.05 \%}}$ & $\underline{\underline{79.54 \%}}$ \\
\hline \multirow[t]{3}{*}{2009} & \multirow[t]{3}{*}{ Dec-09 } & -0.1370 & $\overline{-0.0159}$ & $\overline{-0.0145}$ & -0.0145 & -0.0122 \\
\hline & & & $\underline{0.1211}$ & $\underline{0.1225}$ & $\underline{0.1225}$ & $\underline{0.1248}$ \\
\hline & & oved & $\underline{\underline{88.43 \%}}$ & $\underline{\underline{89.43 \%}}$ & $\underline{\underline{89.40 \%}}$ & $91.10 \%$ \\
\hline \multirow[t]{3}{*}{2010} & \multirow[t]{3}{*}{ Dec-10 } & -0.0639 & -0.0075 & $\overline{-0.0071}$ & -0.0071 & $\overline{-0.0072}$ \\
\hline & & Utility & $\underline{0.0564}$ & $\underline{0.0567}$ & $\underline{0.0567}$ & $\underline{0.0566}$ \\
\hline & & & $88.26 \%$ & $\underline{88.84 \%}$ & $\underline{\underline{88.81 \%}}$ & $\underline{88.67 \%}$ \\
\hline
\end{tabular}




\section{Conclusion}

This paper computes and examines the hedging effectiveness of constant and dynamic optimal hedge ratios in the carbon offset credit market of the EU-ETS from 2008 to 2010. Using daily spot and futures prices from BlueNext and ICE Futures Europe respectively, this paper first employs naïve, OLS, VECM and VECM-GARCH models to calculate hedge ratios. The performance of these hedge ratios are then evaluated based on the variance reduction and utility improvement criteria.

The findings presented in this paper confirm that all models are able to produce variance reduction and utility improvement over the unhedged position. However, there is no consistent evidence that supports the superiority of the more sophisticated, dynamic hedge ratios. More surprisingly, the naïve hedge ratio ( 1 spot=1 future hedge) exhibits a strong performance of variance reduction and utility improvement in some cases. The results presented in this paper generally indicate that a hedger (not limited to emitters) under the EUETS market environment who needs to hedge the price risk of its spot CER credit holding should use OLS over the dynamic hedge ratios, not only due its strong performance in variance reductions but also because of its simplicity and trading cost advantages over dynamic hedge ratios. The conclusion in this study is consistent with Fan et al. (2012), in which it was also found that the simpler time-invariant hedge ratios outperform the more sophisticated time-varying hedge ratios in EUA market. This comes with no surprise as the CER and EUA over the period 2008-2010 have been highly correlated. Therefore, by addressing the gap in the literature, it may seem safe to conclude that, in general, if the objective is to reduce variance, a hedger in the carbon market should always use the OLS model over the more sophisticated models.

The fact that the OLS tends to out-perform the GARCH model is not a new discovery in the hedge ratio literature. A group of researchers including Bystrom (2003), Lien, Tse and Tsui (2002) and Moosa (2003) also support the findings. However, it is also important to take note of the data sample used in this study. Due to the limitations of data availability, our sample period is relatively short (2008-2010), which allowed us only in-sample estimations. Therefore, future research is strongly encouraged to further examine and confirm the hedging effectiveness of the dynamic hedge ratios when more data becomes available. 


\section{References}

2003/87/EC, D. (2003). Directive 2003/87/EC of the European Parliament and of the Council of October 2003 establishing a scheme for greenhouse gas emission allowance trading within the Community and amending Council Directive 96/61/EC. Official Journal of the European Union L275, 32-46.

Baillie, R. T., \& Myers, R. J. (1991). Bivariate GARCH estimation of the optimal commodity futures hedge. Journal of Applied Econometrics, 6(2), 109-124.

Benet, B. A. (1992). Hedge period length and Ex-ante futures hedging effectiveness: The case of foreign-exchange risk cross hedges. Journal of Futures Markets, 12(2), 163-175.

BlueNext (2011). Spot CER. Retrieved 14th February, 2011, from http://www.bluenext.eu/

Byström, H. N. E. (2003). The hedging performance of electricity futures on the Nordic power exchange. Applied Economics, 35(1), 1-11

Chou, W. L., Denis, K. K. F., \& Lee, C. F. (1996). Hedging with the Nikkei Index Futures: the conventional model versus the error correction model. Quarterly Review of Economics and Finance, 36(4), 495-505.

Clean Development Mechanism in China (2010). Approval status of CDM projects in China (up to April 14, 2010). Retrieved 20th April, 2010, from http://cdm.ccchina.gov.cn/WebSite/CDM/UpFile/File2442.pdf

Copeland, L. and Zhu, Y. (2010) Hedging effectiveness in the index futures market. In: Gregoriou, G. and Pascalau, R., eds. (2010) Nonlinear Financial Econometrics: Forecasting Models, Computational and Bayesian Models. Palgrave-MacMillan, 97117

ECX (2010). ICE ECX contracts: EUAs and CERs - getting started: ICE FUTURES EUROPE.

Ederington, L. H. (1979). The Hedging Performance of the New Futures Markets. The Journal of Finance, 34(1), 157-170.

Engle, R. F. (1982). Autoregressive Conditional Heteroscedasticity with Estimates of the Variance of United Kingdom Inflation. Econometrica, 50(4), 987-1007.

Fan, J., Roca, E \& Akimov, A. (2012). Estimation and performance evaluation of optimal hedge ratios in the carbon market of the European Union Emissions Trading Scheme. Australian Journal of Management (forthcoming). 
Figlewski, S., Landskroner, Y. \& Silber, W. (1991). Tailing the hedge: Why and how. Journal of Futures Market, 11(2), 201-212

Ghosh, A. (1993). Hedging with stock index futures: Estimation and forecasting with error correction model. Journal of Futures Markets, 13(7), 743-752.

Ghosh, A., \& Clayton, R. (1996). Hedging with international stock index futures: an intertemporal error correction model. Journal of Financial Research, 19(4), 477-492.

Hilliard, J. \& Huang, P. (2005). An empirical analysis of multi-period hedges: applications to commercial and investment assets. Journal of Futures Markets, 25(6), 587-606.

Kawaller, I. \& Koch, T. (1988). Managing cash flow risk in stock index futures: The tail hedge. Journal of Portfolio Management, 15(1), 67-79.

Kroner, K. F., \& Sultan, J. (1993). Time-varying distributions and dynamic hedging with foreign currency futures. Journal of Financial and Quantitative Analysis, 28(4), 535551.

Lien, D. (1996). The effect of the cointegration relationship on futures hedging: A note. Journal of Futures Markets, 16(7), 773-780.

Lien, D. (2005a). A note on the superiority of the OLS hedge ratio. Journal of Futures Market, 25(11), 1121-1126.

Lien, D. (2005b). The use and abuse of the hedging effectiveness measure. International Review of Financial Analysis, 14(2), 277-282.

Lien, D. (2009). A note on the hedging effectiveness of GARCH models. International Review of Economics \& Finance, 18(1), 110-112.

Lien, D., \& Li, A. (2003). Futures hedging under mark-to-market risk. Journal of Futures Markets, 23(4), 389-398.

Lien, D., Tse, Y. K., \& Tsui, A. K. C. (2002). Evaluating the hedging performance of the constant-correlation GARCH model. Applied Financial Economics, 12(11), 791 - 798.

Malliaris, A. G., \& Urrutia, J. L. (1991). The impact of the lengths of estimation periods and hedging horizons on the effectiveness of a Hedge: Evidence from foreign currency futures. Journal of Futures Markets, 11(3), 271-289.

Moosa, I. (2003). The sensitivity of the optimal hedge ratio to model specification. Finance Letters, 1(1), 15-20.

Myers, R. J., \& Thompson, S. R. (1989). Generalized Optimal Hedge Ratio Estimation. American Journal of Agricultural Economics, 71(4), 858-868. 
Park, T. H., \& Switzer, L. N. (1995). Time-varying distributions and the optimal hedge ratios for stock index futures. Applied Financial Economics, 5(3), 131 - 137.

Sim, A.-B., \& Zurbruegg, R. (2001). Optimal hedge ratios and alternative hedging strategies in the presence of cointegrated time-varying risks. The European Journal of Finance, 7(3), 269 - 283.

United Nations. (1998). Kyoto Protocol to the United Nations Framework Convention on Climate Change. Kyoto, Japan.

World Bank. (2005). State and trends of the carbon market 2005. Washington DC: World Bank Institute.

World Bank. (2006). State and trends of the carbon market 2006. Washington DC: World Bank Institute.

World Bank. (2007). State and trends of the carbon market 2007. Washington DC: World Bank Institute.

World Bank. (2008). State and trends of the carbon market 2008. Washington DC: World Bank Institute.

World Bank. (2009). State and trends of the carbon market 2009. Washington DC: World Bank Institute.

World Bank. (2010). State and trends of the carbon market 2010. Washington DC: World Bank Institute.

Yang, J. W., \& Allen, D. E. (2004). Multivariate GARCH hedge ratios and hedging effectiveness in Australian futures markets. Accounting and Finance, 45(2), 301-321. 